\title{
Estereotipos entre dos mundos. Viajeros alemanes del siglo XIX en España y Marruecos ${ }^{1}$
}

\author{
Berta RAPOSO \\ Universitat de València \\ Berta.raposo@uv.es
}

Recibido: 12 de noviembre de 2013

Aceptado: 22 de enero de 2014

\section{RESUMEN}

La literatura de viajes, como vehículo privilegiado para documentar relaciones interculturales, es rica en diferentes expresiones y ejemplos de tipología analógica, antitética y recíproca, que resaltan las similitudes y las diferencias entre la nación propia y la extraña. En el caso de los viajeros alemanes cuyo destino era originariamente España, pero que luego, por diversos motivos, también visitaron Marruecos, la percepción de diferencias suele ser doble, como intentaremos mostrar en el siguiente artículo. En la tipología presente en estos relatos de viaje, España funciona como punto de partida. La tipología analógica y la recíproca apenas se dan, ya que Alemania como país de origen suele quedar muy lejos.

Palabras clave: Literatura de viajes, interculturalidad, xenología, Reiseliteratur, Interkuturalität, Fremdwahrnehmung.

\section{Stereotypes between two Worlds. German Travellers in Spain and Morocco in the $19^{\text {th }}$ Century}

\begin{abstract}
Travel literature, as an optimal vehicle for the documentation of intercultural relationships, gives us many examples of analogical, antithetic and reciprocal typology. In the case of German travellers whose destination was originally Spain, but who also visited Morocco for several reasons, the perception of those differences uses to be twofold, as we will try to show in the following paper. In most of the cases of the typology shown in these stories about travelling, Spain turns out to be the point of departure more than Germany. The analogical and reciprocal typologies are barely present since Germany (the land of origin) is too far away for the travellers.
\end{abstract}

${ }^{1}$ El presente trabajo se enmarca en el proyecto de investigación del MINECO "Imágenes y estereotipos españoles en libros de viaje alemanes. Evolución histórica entre realidad y ficción interculturales" (HUM2010-17906). 
Keywords: Travel Literature, Intercultural Studies, Xenology.

SUMARIO: 1. Introducción. 2. Viajeros alemanes en España y Marruecos. 2.1. Mohr, el periodista. 2.2. Rolef, el sacerdote 2.3. Hoffmeister, el artista. 2.4. Goeben, el militar. 3. Conclusiones.

\section{Introducción}

La literatura de viajes, como vehículo privilegiado para documentar relaciones interculturales, es rica en diferentes expresiones y ejemplos de tipología (Beller 2006: 119s.) En la tipología analógica, el viajero se limita a describir lo que ve (o cree ver) y hace simples comparaciones entre la nación propia y la extraña. Es la variante más sencilla, la comparación identitaria. En la tipología antitética resalta las diferencias más que los parecidos; aquí es donde aparecen la mayoría de clichés y estereotipos nacionales. De esta tipología antitética suele derivarse a su vez la tipología recíproca, que hace que de los contrastes observados en el extranjero se extraigan conclusiones sobre la identidad propia, aunque no siempre se formulen de manera explícita. En casos complejos, como por ejemplo el de los viajeros cuyo destino era originariamente España, pero que luego, por diversos motivos, también visitaron Marruecos, la percepción de diferencias es necesariamente doble: entre el propio país y España y entre España como segundo punto de partida y Marruecos. A esto se añade en la mayoría de los casos el paso por Gibraltar, que confronta a los viajeros con una tercera nacionalidad insertada en suelo español; y una vez en Marruecos se suma a todo esto la presencia de una etnia existente también en Alemania, pero no España: los judíos. Se plantea entonces la cuestión de si la tipología analógica, antitética y/o recíproca de ahí resultantes se desarrollan a dos o tres bandas (Alemania-España, Alemania-Marruecos o Alemania-España-Marruecos) o si el país de origen queda ya demasiado lejano como para servir de referencia básica para las comparaciones. En las siguientes consideraciones se intentará contestar a esta pregunta mediante una recopilación de pasajes donde predomine la dicción comparativa.

\section{Viajeros alemanes en España y Marruecos}

En el largo período que va de fines de la Edad Media hasta el siglo XVIII, España pasó de ser un lugar remoto en los confines del continente a un país atractivo para los viajeros por el contraste entre su imagen romántica y su proceso de modernización y de acercamiento a Europa. Pero hasta el siglo XIX, los viajeros alemanes raras veces aprovechaban la ocasión para cruzar el estrecho de Gibraltar y poner pie en África. En el siglo XVIII solo uno, el comerciante Franz Jenne, tuvo una breve estancia en Ceuta y Tánger, a la cual dedica cuatro páginas dentro del tercer volumen de sus Viajes (Jennes Reisen nach Spanien, Piemont, der Lombardei und Tyrol, 1790). Aparte de una sucinta descripción del paisaje, su principal interés se centra en temas mercantiles, sin hacer mayores reflexiones culturales o antropológicas. 
En el siglo XIX, con la mejora de las comunicaciones y medios de transporte por un lado, y con la revalorización romántica de España por otro, aumenta considerablemente el número de viajeros alemanes que la visitan, siguiendo los pasos de los franceses e ingleses, que les habían precedido en el siglo XVIII. La mayor parte de ellos llegan hasta el Sur del país (Andalucía), a diferencia de lo que ocurría en siglos anteriores, cuando la ruta más común era solo hasta Madrid. Una vez en Andalucía, no dejaban de tener presente la cercanía del otro continente, que connotaba también un Oriente entendido en un sentido conceptual y no geográfico, que implica "la presencia viva del Islam [...] en la cultura europea" (Llinares 2006: 38). Esta imagen del Oriente, forjada en el siglo XVIII por la traducción de Las mil y una noches de Antoine Galland y las teorías de Johann Gottfried Herder sobre literatura europea medieval, abarcaba todos los ámbitos opuestos al pensamiento progresista de la Ilustración y constituía un universo de representaciones cargado de clichés $(C f$. Thum 2007: 391 y Beller 20207: 317). El Romanticismo siguió alimentando esta imagen, que coexistía en la literatura de ficción y en la de viajes.

La estancia en Andalucía puede considerarse, pues, como "fase de sensibilización" para un posterior desplazamiento a Marruecos. Así lo formula Khalid Lazaare en varios estudios sobre viajeros alemanes a este país en el siglo XIX (Lazaare 1998: passim, y especialmente Lazaare 2007: 325), donde nombra a siete de ellos como los principales, de los cuales solo uno (el príncipe Wilhelm zu Löwenstein 1845) estuvo también en España (García Wistädt 2011: 206-214).

Hay otros cuyos viajes parten igualmente de España y cuya estancia se sitúa ya más avanzado el siglo XIX, (entre los años 60 y 80), cuando las relaciones entre Marruecos y Alemania habían alcanzado un cierto grado de desarrollo (Guillen 1967: passim). Algunos de ellos van a Marruecos con una misión muy concreta, como el oficial del ejército prusiano August von Goeben (1816-1880), que acompañó a las tropas españolas en sus combates junto a Tetuán y en la batalla de Wad-Ras en $1860^{2}$. Otros simplemente se proponen ampliar el horizonte de su viaje a España, como el periodista Wilhelm Mohr, el sacerdote católico Franz Rolef y el escultor Heinz Hoffmeister o aprovechar la ocasión de estar allí para cambiar de continente. Un punto en común entre estos tres últimos es que todos declaran en los prólogos de sus obras que su pretensión es presentar una imagen de España lo más veraz posible, al margen de prejuicios románticos e idealistas. En esto, los tres son defensores, declarados o no, del positivismo reinante en Europa y Alemania a finales del siglo XIX. Para Goeben, en cambio, España era en principio solo tierra de paso hacia su destino militar. Además, conocía el país con anterioridad, pues 22 años antes había participado en la primera guerra carlista. En eso se diferencia sustancialmente de los otros tres, que visitaban Marruecos y España por primera vez. También hay que tener en cuenta que éstos viajaban, o bien solos, o bien en compañía de otros alemanes, mientras que Goeben durante su estancia en Marruecos se movió siempre en un ambiente español: el de los oficiales y soldados del ejército allí estacionado. Por

\footnotetext{
${ }^{2}$ Más detalles sobre su vida pueden encontrarse en BESAS (2010: 246-247).
} 
todo ello, en contra del orden cronológico, presentaremos primero a Mohr, Rolef y Hoffmeister, y a Goeben al final, ya que las premisas de su viaje son muy diferentes.

\subsection{Mohr, el periodista}

Wilhelm Mohr, un periodista que fue corresponsal en España en la época de la tercera guerra carlista, en un momento de pausa en los combates pasó un tiempo en Andalucía, y de allí se desplazó a Marruecos. En el segundo volumen de su relato de viaje Achtzehn Monate in Spanien (1876) dedica seis extensos capítulos a su estancia en ese país. En un prólogo escrito a posteriori explica por qué le interesaba especialmente documentar ese viaje:

Die maurischen Traditionen sind noch immer ein wichtigerer Factor im privaten und öffentlichen Leben Spaniens, als mancher glaubt, und ich weiß aus eigener Erfahrung, daß man die staatlichen Verhältnisse Spaniens ohne Vorkenntniß der Anarchie, des Mangels an Rechtsbewußtsein und des trägen Fatalismus im Mohrenlande eben so wenig verstehen kann, wie die Kunst der Römer ohne die Wissenschaft ihrer griechischen Lehrer und Vorbilder (Mohr 1876: VIIs.).

Lo más destacado de su visión de Marruecos es el lento proceso de atracción, más aún, de fascinación progresiva tras un primer choque cultural causado por la confrontación con un mundo aún más extraño que el español. Recién llegado a Tánger comenta:

Und dort in dieser unbekannten heidnischen, jedes Anklanges an die gewohnte Cultur entbehrenden Welt ist es Einem zuvörderst ganz traurig und verlassen zu Muthe, etwa wie einer armen Seele, die ohne Bädeker die Reise in die andere Welt angetreten hat (Mohr 1876: 210).

Aunque no se pueden negar ciertos toques irónicos en este pasaje (la "pobre alma" sin Bädeker), lo que predomina es una impresión desoladora, una extrañeza absoluta que le impide siquiera hacer comparaciones analógicas ("fern jeder europäischen Analogie"). Pero esto pronto se revela como un recurso retórico, pues en la página siguiente, al describir el aspecto extraño y abigarrado de las gentes y sus vestimentas, recurre a la comparación más próxima que se le podía ocurrir: con el Carnaval de su ciudad natal, Colonia:

Der erste Eindruck, den man von all diesen exotischen Gestalten und lebendigen Brechpulvern hat, ist gar nicht entsprechend zu schildern. Man würde in Köln etwas Aehnliches erleben können, wenn einmal die gesammte Löhrgasse an einem schönen Pfingstmorgen Carneval spielte und Bettzeug und alte Säcke zur Vermummung benutzte. Aber alles in der allergrößten Ernsthaftigkeit und Naivetät (Mohr 1876: 211).

De la tipología analógica se deriva aquí una tipología antitética e incluso recíproca, que en definitiva sugieren que el Carnaval de Colonia es bromista (no serio) y falto de ingenuidad, ya que es la seriedad y la ingenuidad lo que caracterizan esta escena marroquí. Esa misma seriedad e ingenuidad la observa en el guía y traductor 
que le acompaña desde su llegada a Tánger, y cuyas percepciones son totalmente opuestas a las suyas: "[...] statt der Merkwürdigkeiten, auf die wir gespitzt sind, zeigt er uns die Wohnungen der Consuln und Minister. Ihm ist alltäglich, was uns neu, und neu, was uns alltäglich" (Mohr 1876: 212).

El contraste abismal se acentúa porque la anterior estación del viajero había sido Gibraltar, el "Londres español", y una vez en Tánger no es capaz de descubrir nada europeo en lo que los marroquíes llaman "nuestro París": "Hüben die Cultur des Beefsteaks und des ästhetischen und musikalischen Thees, hier die des Kuskuß und des Kiffs" (Mohr 1876: 216), a lo que añade una nota al pie que ya contiene también una comparación entre Marruecos y España, desfavorable a esta última: "Das erstere ein dem fürchterlichen spanischen cocido oder puchero ähnliches, aber viel schmackhafteres Nationalgericht, das zweite ein narkotisches Kraut, das mit Tabak vermischt geraucht wird" (Mohr 1876: 216). La minusvaloración de España aparecía ya antes en una breve observación hecha al llegar al Hotel de France de Tánger, regentado por un francés y "besser eingerichtet als irgend ein Hotel in ganz Spanien" (Mohr 1876: 211).

En general en estas primeras impresiones predomina la tipología antitética, el efecto de diferencia manifestado en el paisaje y la vegetación, que hacen ver al viajero un gran contraste entre Marruecos y España, concretamente Andalucía (la zona de España supuestamente más cercana a Marruecos): "Das Land, die Erde, die Berge dieser Küste sehen nicht im geringsten mehr andalusisch aus, sondern ganz und gar fremdartig und africanisch" (Mohr 1876: 217). Más adelante habla de "Cacteen- und Aloedickichte [...], gegen die alles, was ich in Andalusien gesehen, eitel Treibhausprodukte zu sein schien" (Mohr 1876: 267).

La convivencia de representantes de distintas naciones europeas en Marruecos da ocasión al viajero de relativizar y matizar las diferencias entre unos y otros, siendo los españoles los que mejor se adaptan, según él. En este contexto y en este pasaje Mohr expresa de la manera más cruda los tradicionales prejuicios y estereotipos sobre los españoles y los "moros":

Einige Hundert Europäer haben festen Wohnsitz in Mogador [...]. Es sind fast nur Engländer, Franzosen und Spanier, die sich unter einander wenig vertragen und verstehen. [...] Am besten behagen sich noch die Spanier auf diesem Misthaufen, was kein Wunder ist, da die Mohren fast eben so faul sind wie sie selbst, und die gesellschaftlichen Verhältnisse Marokkos weiter nichts sind als ein Gegenbild derjenigen der eigenen Heimat, abgesehen von der höheren Ursprünglichkeit und Naivetät (Mohr 1876: 236s.).

Los ingleses y franceses, como no podía menos de esperarse, salen bastante mejor parados, y con ellos se entiende el viajero mucho mejor. Resume su impresión de ellos en las siguientes palabras, donde no pierde la ocasión de corroborar de pasada la crítica de los hoteles españoles:

Wir durften übrigens mit den Engländern, die uns sofort zu Thees und musicalischen Unterhaltungen einluden, ebenso zufrieden sein wie mit den Franzosen, in deren Hotel wir besser lebten, als das in ganz Spanien von Irun bis Cadiz möglich sein würde (Mohr 1876: 237). 
Una interesante contraposición entre dos clases diferentes de extrañeza tiene lugar durante una excursión al interior del país partiendo de Mogador.

Nirgends empfindet man so lebhaft wie hier den charakteristischen Unterschied des Erdtheils von dem unsrigen [...] Und wenn man so hinfliegt durch diese neue Welt [...] dann kann man allerdings dazu kommen, sich die Augen zu reiben und sich für irgend einen verwunschenen Prinzen aus einem orientalischen Märchen zu halten, oder sich zu verwundern wie ein Berliner im Siebengebirge (Mohr 1876: 241).

El renano Wilhelm Mohr piensa aquí en el macizo montañoso situado en los alrededores de Colonia y Bonn, y aunque existe ciertamente una diferencia entre este paisaje y las tierras llanas de Berlín, sin embargo la altura media de esos montes (de 300 a 400 metros) hace la comparación un tanto ridícula. Aquí el viajero juega evidentemente con la ironía, presentando a los berlineses como provincianos que se extrañan la primera vez que ven montañas, y ésa es una extrañeza totalmente prosaica; mientras que la otra posibilidad es adentrarse tanto en el otro mundo como para creerse protagonista de un cuento oriental. Mohr, por su parte, no parece identificarse ni con una ni con otra actitud.

Pero el final de su estancia en Marruecos se acerca, y al regresar a Tánger, repite la comparación con Andalucía, que incluso en el clima vuelve a salir malparada: "Während man drüben in Sevilla von allen Seiten und in Gibraltar oder Cadiz mindestens an einer Seite gebraten wird, umweht Einen hier der große kühle Hauch zweier Meere. Der Winter weiß nichts von Kälte, der Sommer nichts von Hitze" (Mohr 1876: 265).

Finalmente, en el momento de la despedida predice para Marruecos un futuro semejante al de España en cuanto a la aproximación y adaptación a estándares europeos/occidentales, terminando con un ejemplo de tipología analógica dirigida al futuro:

Freilich, die Welt geht ihren Gang, und es werden für Marokko auch Tage kommen, wo die Leute andere Neuigkeiten hören oder gar lesen wollen, als aus Tausend und einer Nacht. Die Alten [...] werden dann rebellisch werden und über den zunehmenden Unglauben klagen. [...] Und die Weiber werden unruhig werden und nach Emancipation von ihren Gesichtsmasken schreien [...] und es gibt großes Geschrei, kirchenpolitischen Unfrieden und Culturkampf, - gerade wie bei uns (Mohr 1876: 280).

Es clara la alusión a la lucha por la secularización que entonces se vivía en Alemania, sintetizada en el término "Culturkampf". De aquí se desprende que también en la timidez de esas tendencias modernizadoras se muestra la afinidad entre España y Marruecos, no solo en las "maurische[n] Traditionen" (v. supra).

\subsection{Rolef, el sacerdote}

Franz Rolef, un sacerdote católico que además era profesor de lenguas modernas en la Universidad de Freiburg, en sus Reisebriefe aus Spanien und Marocco (1885), relata las experiencias de una estancia muy breve (solo tres días), pero inten- 
sa. La percepción del contraste se articula en primer lugar entre Gibraltar y Tánger: "Welcher Unterschied zwischen Gibraltar und Tanger in vier Stunden! Es ist gerade, als wenn man in vier Stunden von Paris nach Peking versetzt würde" (Rolef 1885: 135).

La tónica dominante de su visión está determinada por el prisma religioso, lo cual se manifiesta incluso en la siguiente comparación entre la indumentaria de los musulmanes y la de las órdenes católicas:

Ueber die Kleidung der Muhamedaner habe ich noch zu bemerken, daß sie meistens eine Kutte mit einer Kapuze tragen, wie die Franziskaner; die reichen Mauren aber tragen diese Kleider von weißer Wolle, so daß sie wie Dominikaner aussehen. Da nun die Weiber wie die Nonnen des Carmeliterordens aussehen, so macht die Stadt Tanger den Eindruck eines großen Klosters (Rolef 1885: 139).

El prisma religioso es tan poderoso que no solo produce esta paradójica visión de Tánger como un convento, sino que en esa misma ciudad se percata también de la universalidad del catolicismo, lo cual le hace confirmarse más todavía en sus creencias:

Niemals ist mir die Schönheit der katholischen Kirche in ihrer wunderbaren Einheit so zum Bewußtsein gekommen, wie hier. Man denke sich, die katholischen Gesandten der Länder von Amerika, Belgien, Brasil, Frankreich, Italien, Portugal und Spanien mit ihren Familien und die verschiedenen Katholiken von Deutschland, England und Holland vereinigen sich hier im gemeinschaftlichen Gebet und Ritus in einer afrikanischen Kirche und wohnen dem Amte eines Priesters aus Deutschland bei, wobei der Diacon ein Italiener und der Subdiacon ein Baske ist. Kann man sich ein schöneres Schauspiel denken? Wo in aller Welt in welcher anderen Confession wäre das möglich? (Rolef 1885: 145).

De esta alabanza del catolicismo pasa a una crítica del protestantismo, para la cual se sirve de otra comparación, no solo de religiones, sino también de regímenes políticos, de la cual resulta una nueva paradoja, consistente en que el emperador de Marruecos es declarado como más tolerante que el gobierno republicano de la ciudad suiza de Basilea ${ }^{3}$ :

[...] welche, so viel ich weiß, den 20.000 Katholiken der Stadt Basel das Läuten der Glocken in der katholischen Kirche verbietet und den Ordensgeistlichen das Unterrichtgeben in den Schulen untersagt. Die Katholiken der hiesigen Stadt [Tanger, B. R.], die aus allen Nationen der Welt zusammengesetzt sind, können hier ungehindert ihre religiösen Pflichten erfüllen (Rolef 1885: 145).

También su visión de los judíos, a quienes primero compara con los judíos europeos ("Die Juden [...] sind kräftige, schön gebaute Leute, viel größer als in

${ }^{3}$ Recuérdese que Rolef era profesor de la Universidad de la católica ciudad de Freiburg im Breisgau, no lejos de la protestante Basilea. 
Europa”, (Rolef 1885: 139), le trae una reminiscencia de la historia de la católica España:

Der apostolische Vikar erzählte mir in Betreff der hiesigen Juden, daß jedes Jahr hunderte derselben nach Europa reisen, um sich dort taufen zu lassen, weil ihnen das viel Geld einbringt, und - ihre jüdischen Ostern feiern sie in Tanger ${ }^{4}$ Wer denkt da nicht an die spanische Inquisition, die gerade deshalb von spanischen Königen eingesetzt wurde, weil viele der getauften Juden und Mauren heimlich ihre alten Religionsgebräuche auszuüben fortfuhren (Rolef 1885: 139).

Aunque de manera implícita, Rolef no da aquí ninguna muestra de desaprobación de las prácticas inquisitoriales del pasado. Por último, poco antes del regreso a España vuelve a comparar religiones:

Während das Christentum für alle Bedürfnisse des menschlichen Lebens sorgt und Erquickung bringt, bleibt der Maure gefühllos gegen Leidende. Der Islam hat bis jetzt noch kein Spital hervorgebracht, so wenig als die Philosophie eine barmherzige Schwester [...] Und wie ist das Loos der Frauen und Gefangenen? Letztere läßt man einfach verhungern (Rolef 1885: 147).

Ello no le impide sin embargo mostrarse extraordinariamente crítico con el catolicismo español, que según él se queda sólo en la superficie, no profundiza en la verdadera fe, y además pone de manifiesto la incultura de gran parte del país. Así pues, el punto de partida para Rolef no es la nación (Alemania o España), sino la religión (el catolicismo).

\subsection{Hoffmeister, el artista}

El escultor Heinz Hoffmeister titula su libro de viajes Durch Süd-Spanien nach Marokko. Tagebuchblätter (1889), y su estancia en Marruecos también es muy breve: del 14 al 22 de abril de 1888. Sin embargo, sus observaciones son más extensas y variadas que las de Rolef. También se diferencia de Mohr en que su actitud es desde el principio muy abierta y benevolente frente a Marruecos, pero no así frente a España. En el prólogo había anunciado su intención de desmitificar la imagen romántica de este país, excesivamente idealizada en su opinión, y a lo largo de su viaje se muestra muy crítico en general, hasta que en el Sur del país y especialmente en Andalucía encuentra por fin la confirmación de las expectativas creadas por esa visión romántica y se desdice de todas las críticas negativas hechas con anterioridad. Ha llegado ahí a la ya nombrada fase de sensibilización.

Finalmente en Marruecos, al describir la impresión causada por la belleza de la bahía de Tánger (que compara con el golfo de Nápoles) llega hasta la exaltación y la exageración:

\footnotetext{
${ }^{4}$ Las cursivas son de la autora.
} 
Ich muß gestehen, daß ich wie gebannt auf der Terrasse stehen blieb, und nicht wußte, ob ich den Golf von Neapel vor mir habe, oder eine fata morgana mir ein Zauberbild vorspiegele. [...] Ich konnte es nicht fassen, was ich erblickte, der Anblick überwältigte mich so, daß sich meine Augen trübten und all mein Empfinden - ich schäme mich nicht, es zu sagen - in einer Thräne sich auflöste (Hoffmeister 1889: 151).

Poco tiempo después España le aparece ya, como a Mohr, muy lejana y distante:

Nur ist es schier hier unfaßlich, wenn ich nach Spanien hinüberschaue, wo bei klarer Luft die Häuser zu erkennen sind, daß hier die Welt so ganz anders ausschaut, wie da drüben. [...] Oft komme ich mir wie verzaubert vor. Die Blumen, welche ich in Spanien so sehr vermißt, überwuchern hier vollständig das Land (Hoffmeister 1889: 164).

En general, la fascinación experimentada por Hoffmeister en Marruecos se limita al paisaje y a la naturaleza, mientras que la percepción antropológica es mucho más crítica. Tampoco falta aquí una comparación de los judíos marroquíes con los europeos:

So leicht es mir auch wird, in Deutschland einen Juden oder eine Jüdin zu erkennen, hier, sowie auch in Tunis, Egypten, und Palästina, bringe ich es schwer fertig. [...] Es ist in total anderer Typus als wir ihn zu sehen gewohnt sind. Die Jüdinnen haben runde, ich möchte fast sagen deutsche Gesichter [...] Die Männer haben meist schön geschnittene Züge und viele erinnerten mich an Büsten aus der griechischen Blütezeit. Nur in der Haltung und im Gang scheinen sie sich alle zu gleichen (Hoffmeister 1889: 157).

El sentimiento de lejanía reaparece a su vuelta a Gibraltar:

$[\ldots]$ ich muß gestehen, daß es einen nicht geringeren Eindruck auf mich machte, so plötzlich diese europäischen Verhältnisse wieder um mich zu sehen, wie vordem in Marokko, wo ich ebenso schnell und unerwartet mich unter farbigen Costümmenschen, Schlangenbändigern, kurz in einer total anderen Welt befand. Es ist wirklich eine großartige Erscheinung in Zeit von zwei bis drei Stunden, an Land, Leuten und Sitten eine solche Verschiedenheit zu sehen (Hoffmeister 1889: 172).

Pese al título del libro de Hoffmeister, que parece sugerir que Marruecos sea el objetivo final del viaje (Durch Süd-Spanien nach Marokko), los capítulos dedicados a España (y no solo al Sur del país) son tan extensos que puede afirmarse que lo que en realidad le interesa al autor es una comparación en toda regla entre ambos países, comparación que en general tiende a rebajar a España frente a Marruecos 5 .

${ }^{5}$ Esta minusvaloración puede ser reflejo de un prejuicio secular, pues desde finales de la Edad Media hasta el siglo XVIII nos encontramos con viajeros que, con el fin de denigrar al catolicismo español, califican a los españoles como peores que los "infieles" (RAPOSO 2012: 113-115). 


\subsection{Goeben, el militar}

El teniente general August von Goeben dio cuenta de sus experiencias hispanomarroquíes en sus Reise- und Lagerbriefe aus Spanien und vom spanischen Heere in Marokko (1863/1864). Todo hace pensar que se trata de una ficción epistolar, ya que en ningún momento ni en ningún lugar se encuentran indicios sobre el/la destinatario/a de las supuestas cartas, ni alusiones personales, o apóstrofes al lector. A pesar de su profesión, Goeben, que va acompañado en el viaje por otros dos oficiales prusianos, no solo se interesa por asuntos militares, sino que observa con todo detalle los aspectos más variados de las tierras por donde pasa ${ }^{6}$, de manera que la descripción del trayecto por el sur de Alemania, Francia y España hasta Marruecos ocupa una gran parte del texto. Pero nunca pierde de vista su objetivo, tanto en el sentido militar como en el cultural. En Marsella, donde va a embarcarse rumbo a Alicante, declara que el Sur es para él como una segunda patria, y ya antes de llegar ahí está atento a los más mínimos indicios que anuncian el cambio de paisaje, de vegetación y de clima:

In Lyon schon fühlten wir uns in den Süden versetzt, so weich und warm war die Luft bei hellem Sternenhimmel. [...] Der Morgen fing an zu grauen. Ich spähte umher, glaubte im Halbdunkel schon hie und da eine Pflanze des Südens in den Feldern und Gärten zu erkennen. Ich lehnte mich wieder zurück, sah mich umgeben von Aloes und Palmen in wunderlichen Riesen-Gestalten (Goeben 1863: 12s.).

Llegado a Alicante, su primera estación en suelo español, siente gran alegría al encontrarse de nuevo en el país de sus recuerdos de juventud. Ya ahí percibe la cercanía de África y aprovecha la ocasión para extenderse a lo largo de tres páginas sobre la historia de los árabes en Murcia y Alicante, las regiones que, en su opinión, están climáticamente más próximas a África. En cambio a su llegada a Madrid constata no sin cierto desencanto que en comparación con su estancia en 1838, la ciudad se ha europeizado:

Madrid! Wie romantisch regte dieser Name von jeher die Phantasie an: die Hauptstadt Spaniens, des glühenden poetischen Spaniens, Afrika fast ebenso sehr wie Europa angehörend! Und wie prosaisch nüchtern liegt nun dieses Madrid vor uns, eine europäische Hauptstadt, wie es deren so viele andere giebt, nichts mehr und nichts weniger (Goeben 1863: 50).

La expresión "Afrika fast ebenso sehr wie Europa angehörend" abunda en el tópico tradicional "África empieza en los Pirineos", de lo cual Goeben es perfectamente consciente, y así lo expresaba ya en un pasaje anterior, cuando al buscar alo-

${ }^{6}$ Sobre su anterior estancia en España Goeben escribió Vier Jahre in Spanien. Die Carlisten, ihre Erhebung, ihr Kampf und ihr Untergang. Skizzen und Erinnerungen aus dem Bürgerkriege. Hannover: Hahn 1841. Existe traducción española de José Ángel Zubiaur: Cuatro años en España. Los Carlistas, su levantamiento, su lucha y su ocaso. Esbozos y recuerdos de la Guerra Civil. Prólogo y notas L. R. Hernández. Pamplona: Institución Príncipe de Viana 1966. (Cf. BesAs 2010: 242-243). 
jamiento en Alicante comentaba sobre un hotel "ein stattliches Gebäude, im europäischem Styl. Ganz unwillkürlich schreibt man hier, als ob man sich schon außerhalb Europa befände" (28). Durante el viaje de Alicante a Madrid por ferrocarril observa que este medio de transporte ha contribuido en gran manera a hacer desaparecer a los salteadores de caminos que hacían tan "románticos" los viajes por España:

$[\ldots]$ jene Banden, $[\ldots]$ welche früher zur Romantik des Reisens in Spanien so wesentlich beitrugen. Die Eisenbahn ist dem freilich weniger förderlich. Auf ihr wird man sich dessen kaum bewußt, daß man sich in einem Lande befindet, welches bisher fast nur dem Namen nach Europa angehörte (Goeben 1863: 48).

En Andalucía sin embargo siente de nuevo la presencia de lo árabe, y esta vez de manera mucho más intensa que en Alicante, haciendo largas digresiones sobre la historia de los árabes en España, especialmente en Córdoba, Sevilla y Gibraltar. Aquí ha entrado ya en la "fase de sensibilización" previa a su paso a Marruecos.

Una vez cruzado el Estrecho, al principio se preocupa sobre todo por cuestiones prácticas de intendencia, pero una vez instalado en el campamento junto a Tetuán, pasa a describir las posiciones militares de los contendientes, y eso le recuerda las antiguas guerras entre españoles y moros: "Da ist denn mit den Spaniern die furchtbarste Vewüstung eingezogen; es ist, als ob die Reminiscenzen der alten MaurenKriege hier wieder aufgelebt wären" (Goeben 1863: 237).

Después de la toma de Tetuán por los españoles, al entrar en la ciudad con el general Prim, las murallas le recuerdan a las murallas medievales de algunas ciudades alemanas ("sie haben die größte Ähnlichkeit mit den mittelalterlichen Mauern mancher deutschen Städte", (Goeben 1863: 262), la Kassbah le hace pensar en castillos medievales alemanes ("Die Kassaba ist eine sehr solid gebaute und vorzüglich erhaltene Burg, in jeder Hinsicht an unsere deutschen mittelalterlichen Burgen und Schlösser erinnernd", (Goeben 1863: 278). La Edad Media es el punto común de referencia que utiliza luego para comparar todo Tetuán con las ciudades andaluzas, y partiendo de ahí extenderse al recuerdo de la historia de los árabes en España:

Lebhaft erinnerte es mich an die Städte, welche wir in Andalusien gesehen [...] Gleich fast allen Städten des Orients oder, genauer gesprochen, der muhamedanischen Welt ist Tetuan stationair geblieben; es ist noch dasselbe wie zu der Zeit, als die spanischen Araber hier ihre neue Niederlassung gegründet hatten, es ist daher in demselben Zustand, in dem zu jener Zeit auch die Städte dieser Araber auf der Halbinsel sein mußten, die sich dann unter dem Einfluß christlicher Sitte und europäischer Gesittung zu den jetzigen spanischen Städten entwickeln konnten (Goeben 1863: 263).

Algo semejante ocurre con los habitantes, para quienes no vale el desfase cronológico observado en las ciudades (España se ha cristianizado y evolucionado en ese sentido, Marruecos permanece igual), por mucho que les pese a los españoles:

Und entsprechend dem Grund-Charakter der Stadt ist auch der Typus ihrer Einwohner, der wirklich maurischen Einwohner, ganz derselbe wie der der Andalusier und 
Murcianer. Sie könnten für Ein Volk gelten. Selbst Spanier, welche gewiß sehr wenig geneigt sind, solche Aehnlichkeit mit den verachteten Moros anzuerkennen, Spanier nämlich aus der nördlichen Hälfte der Halbinsel, habe ich dieses mit Erstaunen aussprechen gehört (Goeben 1863: 263).

Esta afinidad la observa Goeben también en la tendencia a la hipérbole (rasgo típicamente oriental, según él) que se hace patente en la actitud de los españoles ante las victorias obtenidas contra los marroquíes: "[...] die Spanier malen sich selbst immer ihre Erfolge in möglichst glänzenden Farben aus, sie können ihrer Natur nach nicht anders; auch etwas von jener orientalischen Phantasie ist ihnen geblieben" (Goeben 1863: 267). En ese mismo contexto bélico encontramos una de las escasas comparaciones directas entre españoles y alemanes:

Einen höchst merkwürdigen Gegensatz zu dem geräuschvollen Treiben der Deutschen und ebenso der Franzosen im Lager und im Felde bildet die Art und Weise der spanischen Soldaten. Nie hört man hier das laute lustige Lärmen, wie es anderwärts an der Tagesordnung ist; nie sieht man auch nur einen einzelnen Angetrunkenen (Goeben 1864: 21).

El viaje de vuelta a España suele ocasionar en todos estos autores una nueva percepción de diferencias con el Marruecos subdesarrollado. Aunque éste es el caso de Goeben recién llegado a Cádiz ("Im Gegensatz zu dem trotz allem Bemühen doch immer noch schmutzigen Tetuan machten uns die so sauber gehaltenen Straßen von Cadiz jetzt doppelt behaglichen Eindruck", (Goeben 1864: 241), sin embargo en Sevilla se confirma la impresión de afinidad entre Andalucía y Marruecos:

Ueberhaupt frappirt uns auch hier wieder, wie es ja auch bei unserem Eintreffen in Tetuan in so hohem Grade der Fall war, die überraschende Aehnlichkeit zwischen den, nun doch beinahe vierhundert Jahre lang so streng geschiedenen Ländern auf beiden Seiten der Meerenge (Goeben 1864: 250).

Esta afinidad abarca tanto lo climático-paisajístico como lo antropológico. Se trata de "Theile eines einst einheitlichen Ganzen [...] mit gleichem Klima und gleichen Produkten", y los habitantes de ambas partes son "augenscheinlich so nahe verwandt", sus casas y ciudades "ganz gleichartig". La única diferencia es la religión:

Der Gegensatz der Religionen allein ist es, welcher sie scheidet und durch den in Folge der damit verbundenen abweichenden Lebensweise und Entwickelung die jetzt sich geltend machenden Verschiedenheiten im Lauf der Jahrhunderte wesentlich hervorgerufen wurden (Goeben 1864: 250).

En general, Goeben muestra la actitud más abierta de todos los viajeros presentados, tanto frente a España como frente a Marruecos. Con España se había familiarizado ya en su juventud, y en cuanto a Marruecos, pese a encontrarse allí acompañando a los ocupadores españoles, no contempla el país con enemistad, sino con aprecio y respeto. 


\section{Conclusiones}

En los casos de tipología analógica y antitética presentes en estos relatos de viaje España suele funcionar como punto de partida, ya que Alemania como país de origen queda ya muy lejos para los viajeros. La tipología analógica se da sobre todo en comparaciones entre España y Marruecos; la tipología antitética, en comparaciones entre Marruecos y Europa. Por otro lado, la tipología recíproca apenas está presente; las observaciones implícitas o explícitas sobre Alemania se limitan a breves momentos o flashes. Dado que en la tipología antitética, como se ha observado al principio, es donde más abundan los clichés y estereotipos nacionales, nos centraremos en las siguientes conclusiones sobre ella.

Cuando un viajero alemán procedente de España es confrontado con Marruecos, un país todavía más exótico y más extraño a sus ojos, podría pensarse que, por contraste, España se le aparezca como europea y relativamente civilizada. Pero no suele suceder así. En el siglo XIX, nuestro país ya había perdido mucho de ese encanto romántico a los ojos de algunos viajeros, sin haber adquirido todavía el nivel y los adelantos que se esperaban de un país europeo normalizado. En este aspecto, se encontraba en desventaja frente a Marruecos, que, pese a todo su atraso y escaso grado de civilización, todavía resultaba atractivo en su "originariedad" e "ingenuidad" ("Ursprünglichkeit" y "Naivetät", en palabras de Wilhelm Mohr), por lo cual no es infrecuente que España salga malparada en algunas de estas comparaciones.

Además, en Marruecos los viajeros descubrían los originales del pasado islámico de España, confirmando así la afinidad de caracteres entre ambos países. Pero la estancia previa en el Gibraltar británico y la experiencia del paso del Estrecho avivaban la conciencia de la separación entre los dos continentes, que se veían como mundos opuestos no solo geográficamente. $Y$ pese a su pertenencia geográfica a Europa, España quedaba a medio camino entre ambos mundos, sin apenas participar de los aspectos positivos de cada uno de ellos, atrapada como estaba en los estereotipos generados por su afinidad histórica con Marruecos.

\section{Referencias bibliográficas}

BelLeR, M., «Typologia reciproca. Über die Erhellung des deutschen Nationalcharakters durch Reisen», en: Eingebildete Nationalcharaktere. Vorträge und Aufsätze zur literarischen Imagologie. Göttingen: V + R Unipress 2006, 105-124.

Beller, M., «East / West», en: Beller, M. / J. LeERssen (eds.), Imagology. The Cultural Construction and Literary Representation of National Characters: A Critical Survey. Amsterdam: Rodopi 2007, 315-319.

Besas, P., Compendium of German-Language Books of Travel in Spain (1750-1900). Madrid: Ediciones La Librería 2010.

GARCíA WistäDT, I., «Krieg und Romantik. Vom spanischen Unabhängigkeitskrieg bis zur deutschen Märzrevolution», en: RAPoso FernÁNDEZ, B. / GuTIÉRREZ KoESTER, I. (eds.), Bis an den Rand Europas. Spanien in deutschen Reiseberichten vom Mittelalter bis zur Gegenwart. Frankfurt am Main/Madrid: Iberoamericana, Vervuert 2011, 167-225. 
Goeben, A. v., Reise- und Lagerbriefe aus Spanien und vom spanischen Heere in Marokko. Vol. 1. Hannover: Hahn'sche Hofbuchhandlung 1863.

Goeben, A. V., Reise- und Lagerbriefe aus Spanien und vom spanischen Heere in Marokko. Vol. 2. Hannover: Hahn'sche Hofbuchhandlung 1864.

Guillen, P., L'Allemagne et le Maroc de 1870 à 1905. París: Presses universitaires de France 1967.

HoffMeISTER, H., Durch Südspanien nach Marokko. Tagebuchblätter. Berlín: Richard Wilhelmi 1889.

LaZAARE, K., Marokko in deutschen Reiseberichten des 19. und beginnenden 20. Jahrhunderts. Vorstudien zur deutschen Wahrnehmung einer islamischen Region. Frankfurt am Main et al.: Peter Lang 1998.

LAZAARE, K., «Das/Ein Bild Marokkos in deutschen Reiseberichten des 19. Jahrhunderts», en: Valentin, J. M. / J. F. CANDONi (eds.), Akten des XI. Internationalen Germanistenkongresses.- Paris 2005. Vol. 9. Divergente Kulturräume in der Literatur - Kulturkonflikte in der Reiseliteratur. Frankfurt am Main et al.: Peter Lang 2007, 323-330.

LLINARES, J. B., «Edward W. Said y la reflexión sobre Europa», Recerca. Revista de pensament $i$ anàlisi 6 (2006), 37-63.

Mohr, W., Achtzehn Monate in Spanien. Köln: DuMont-Schauberg 1876.

RAPOSO, B., «Spanienreisende zwischen Okzident und Orient am Ende des 18. Jahrhunderts», en: BENísKovÁ, B. (ed.), Interkulturalität in Sprache, Literatur und Bildung. Pardubice: Univerzita Pardubice 2012, 111-117.

Rolef, F., Reisebriefe aus Spanien und Marocco. (November 1883 bis April 1884): ein Beiträg zur Kenntniss spanischer Zustände. Freiburg im Breisgau: J. Dilger 1885.

Thum, B., "Orientalism», en: Beller, M. / J. LeERssen (eds.), Imagology. The Cultural Construction and Literary Representation of National Characters: A Critical Survey. Amsterdam: Rodopi 2007, 389-393. 